\title{
Editorial to the Supplementary Special Issue on COVID-19 Law: breadth, depth and future implications
}

\author{
Mark L Flear \\ Queen's University Belfast \\ Correspondence email: m.flear@qub.ac.uk
}

\section{INTRODUCTION}

$\mathrm{T}$ The COVID-19 pandemic, now approaching its third year, is a question for epidemiology, behavioural psychology and politics. It is also a question for law. Action to deal with COVID-19 has important legal dimensions. Many of these are national - or even sub-national - for example, the different laws and guidelines on COVID-19 across the four nations of the United Kingdom (UK). But those laws have to be adopted in the context of a multilevel web of international legal relations. The World Health Organization's International Health Regulations (2005) (IHR) are central to this response. It is under the IHR that COVID-19 became a 'Public Health Emergency of International Concern'.

The pandemic is far from over. While many of the wealthier countries in the world, usually in the global North, have benefited from hugely successful mass vaccination on a scale and speed never seen before, there are clear signs that the coming months will prove difficult, with several countries seeing the reintroduction of precautionary measures. Meanwhile, the pandemic is producing an even more terrible toll of suffering and death in many of the poorest countries in the world, mostly found in the global South. The ninth meeting of the IHR Emergency Committee only underscored the need for continued caution and vigilance against COVID-19.1

It is against the backdrop of the continuing COVID-19 pandemic that the Northern Ireland Legal Quarterly is proud to bring together and publish a range of its past ${ }^{2}$ and upcoming ${ }^{3}$ contributions on the topic as a supplementary special issue, in addition to our four standard issues a year. The past contributions in particular were attempting

1 World Health Organization, Statement on the ninth meeting of the International Health Regulations (2005) Emergency Committee regarding the coronavirus disease (COVID-19) pandemic.

2 Details of past publication are supplied where necessary via an asterisked note on the first page of republished contributions in the special issue.

Here 'upcoming' means not yet published in a standard issue of the journal. 
to contribute to a still unfolding set of events. What unifies all these contributions is how they each have something original and important to say about the legal response to the pandemic that could be termed 'COVID-19 law'.

The contributions to this supplementary special issue underline the breadth and depth of COVID-19 law. It covers legal arrangements at various levels of governance, across a range of substantive areas, and with multiple implications that will continue to attract much attention in the years ahead. The latter include, but are not limited to, the following:

- law and constitutionalism;

- devolution, difference and fragmentation in the laws of the four parts of the UK;

- how public health emergencies reshape or recast rights and responsibilities;

- whose voices count in constructing legal responses;

- power, position and vulnerability; and

- justice, equity and fairness.

In the following sections, I provide an overview of the contributions, trace some thematic connections and outline their implications. It is anticipated that the contributions to this supplementary special issue will help stimulate further discussion about the legal response to current and future crises during the years ahead.

\section{ARTICLES}

Article contributions are organised into those considering COVID-19 law at various levels of governance in the UK and those focusing on particular legal issues.

\section{Developments at different levels of governance in the UK}

The articles in this first group discuss matters relevant to law and constitutionalism. The first offering in this selection, an upcoming article by Moosavian, Walker and Blick, considers UK-level coronavirus legislation. The authors argue that the approach to legislation has moved from regression to panic and, moreover, evidences a disdain for constitutionalism. Specifically, instead of utilising core legislation, including the all-encompassing Civil Contingencies Act 2004 (CCA 2004) and the sectoral Public Health (Control of Disease) Act 1984 (PHA 1984), the UK government instead panicked in the face of the COVID-19 pandemic to introduce the Coronavirus Act 2020 (CA 2020) through the Westminster Parliament at breakneck speed (seven days), followed by a four-week recess. The UK government also introduced 
regulations under the PHA 1984. In reflecting on these key components of COVID-19 law in the UK against the backdrop of pre-existing laws, the authors argue that the selection of legal instruments and the design of their contents are not only poorly judged, but that, in side-lining the CCA 2004, the UK government has wrought significant damage to the UK's constitutional fabric. This analysis contributes much toward the discussion on the legal response to the pandemic and the evolution of constitutionalism in the UK.

Next, Holder looks at some of the implications of the CA 2020 for the law in Northern Ireland. As he explains, the CCA 2020 contains specific provisions for Northern Ireland and also adds a new temporary section in the Public Health Act (Northern Ireland) 1967 (PHANI 1967). The modified PHANI 1967 provides the legislative basis for the Health Protection (Coronavirus, Restrictions) Regulations (Northern Ireland) 2020, which were laid before the Northern Ireland Assembly and came into force on 28 March 2020.

While the law in the area of COVID-19 has been fast moving in Northern Ireland, as it has elsewhere, and continued to develop after the original publication of this article, the point made in it remains important and timely. That is, from the perspective of law in Northern Ireland, which is now in its centenary year, COVID-19 legislation can be understood as in some ways a continuation of a pattern of law stemming from the very creation of the jurisdiction, from so-called special powers in 1922, to Troubles-era legislation, and more specific legislation introduced post-9/11.

Further, just as that legislation raised concerns, COVID-19related legislation in Northern Ireland raises concerns around issues including: legal certainty through its vague, expansive and arbitrary wording, including the 'stay at home' rule; maintenance of the rule of law, including through limited democratic discussion in the Assembly, public dissemination and transparency, given the months-long delay in official publication online; gaps between announcements of changes to the law and the changes actually being made; and the excessive use of fines and other enforcement measures by the Police Service of Northern Ireland against Black Lives Matter anti-racism protests on Saturday 6 June 2020. Although apparent across the articles in this section, this article in particular highlights the importance of public health emergencies in the reshaping or recasting of rights and responsibilities. This and the following article add to this discussion by further highlighting both the importance of devolution settlements to determining rights and responsibilities and their development in response to wider forces that intersect with the specifics of each jurisdiction. 
Indeed, the specifics of devolved law-making are brought into even clearer relief in the new article by Harrington, Hughes Moore and Thomas. They argue that the contemporaneous challenges of the COVID-19 pandemic and Brexit have invigorated steps - conscious or otherwise - towards a Welsh health law. Beginning with the original devolution settlement for Wales in 1998, there has been growing divergence from the approach taken in other parts of the UK. This has been seen in Welsh measures on organ donation, tobacco control and the structure of the health service, and made even more apparent throughout the pandemic. The authors consider the specific values for a coherent and singular body of Welsh health law, which would not only underpin and underline its difference from other health laws elsewhere in the UK, but could provide the foundations for further developments and possible divergence.

The discussion of legal developments in Northern Ireland and Wales also underscores the relevance and evolving nature of devolution, which is creating differences in law across the UK. Much of the legal scholarship on COVID-19 relating to the UK, cited in these contributions, may take an Anglo-British frame for granted and largely overlook devolution. ${ }^{4}$ Scholarship that focuses on law at the devolved level of governance may help to widen and diversify this frame.

\section{Specific issues relating to the COVID-19 pandemic and legal responses}

The second group of articles, focusing on specific legal issues rather than COVID-19 law itself at particular levels of governance, begins with Antova's discussion of disability and COVID-19. In this new article, Antova argues that grassroots disability ethics can be used to improve legal and policy responses to the pandemic. The author points to the importance of different approaches to ethics, in particular those emerging from individuals and groups who tend to be deemed 'lay' as opposed to those 'experts' whose expertise and knowledge are credentialised. More deeply, Antova's argument for the development of ethics from the grassroots points to the significance of diversifying ontologies and epistemologies, and in turn methodologies, to better understand and shape legal and wider responses to acute public health problems and, wider still, to other kinds of problems, whether in the public health domain or beyond. This article raises the key question of whose voices count in the crafting and implementation of legal responses to COVID-19 and, indeed, closely related questions of power, position and vulnerability. Grassroots disability ethics appears to hold

4 M Brazier and J Montgomery, 'Whence and whither "modern medical law"?' (2019) 70(1) Northern Ireland Legal Quarterly 5. 
real potential to empower, reposition and reduce the vulnerability of those disabled within dominant modes of law and policy making. This may in turn improve the justice, equity and fairness of legal and policy responses.

These kinds of questions and concerns also find resonance in McMahon's article. This focuses on the jurisdiction of Ireland to consider the legal avenues available to national governments for compulsory licensing of patented health-technologies for COVID-19, in instances where patent holders either refuse to license such technologies or refuse to do so under reasonable conditions. The article was published in the second half of 2020, just as attention was turning to securing effective vaccines and treatments for COVID-19. The author argues that it is incumbent upon the Irish government, and other national governments, to re-evaluate the current operation of such licensing mechanisms to ensure that they are effective within the context of the pandemic in maintaining access to vaccines and treatments.

The discussion is thus of relevance outwith Ireland. Indeed, it resonates with calls for compulsory licensing and the waiver of intellectual property rights by member states of the World Trade Organization under its Agreement on the Trade-Related Aspects of Intellectual Property (TRIPS), which sets minimum standards for protecting intellectual property. These calls aim to ensure fair and equitable access to vaccines and treatments for COVID-19 around the world, especially in poorer countries that are overwhelmingly in the global South. TRIPS meant it became harder for poorer countries in particular to import generic versions of patented life-saving antiretrovirals to treat people with HIV in place of more expensive patented versions. McMahon highlights the importance of power, position and vulnerability and charts some ways forward towards the resolution of these and related important issues of justice, equity and fairness.

In their article, Hudson and Wragg also advance discussion on justice, equity and fairness, by reference to related intellectual property issues in the context of copyright law and education during the COVID-19 pandemic. While the focus is on higher education in the UK, many of the authors' ideas are relevant to primary and secondary education in the UK and, wider still, to education in other countries. Hudson and Wragg consider whether the impact of the COVID-19 pandemic could justify new limitations or interventions in UK copyright law so that higher education institutions can serve the needs of their students. Various suggestions for using exceptions in the Copyright, Designs and Patents Act 1988 are discussed, in particular, fair dealing and the exemption for lending by educational establishments. 
Overall, the article argues that a public interest defence to copyright infringement, to the extent it still exists in UK law, may not be available, but that it may still be relevant to remedies. In addition, the authors argue that compulsory licensing, although permissible under international copyright law, is not a desirable intervention, and as such, instead, expanding the range of legislative exceptions to encourage voluntary collective licensing would be attractive. The article's resonance will outlast the pandemic in that, as the authors explain, the current emergency only underscores issues with the prevailing model for academic publishing and may speed up the turn by universities towards in-house and open access publishing and for a wider range of material than hitherto.

Ward's upcoming contribution rounds out the articles and looks to the past to reflect on COVID-19 law and the lessons for constitutionalism. In doing so, Ward points to the importance of human nature in shaping legal responses to rare and allegedly unpredictable public health emergencies. Resonating in particular with Moosavian et al's contribution, Ward explains how the panicked response of government came after repeated warnings that the UK was ill prepared for what many experts have said was an inevitable pandemic. In the absence of any planned mitigation, and as seen in the past, government resorts to measures designed to reduce public life to its barest state. In placing legal responses to the COVID-19 pandemic within a longer historical setting, this article provides powerful support for renewed efforts to build resilience into government responses for inevitable future public health emergencies.

\section{COMMENTARIES AND NOTES}

Finally, we have two contributions to Commentaries and Notes, both of them previously published in the journal, and which remain highly relevant to the present pandemic. Indeed, both contributions provide lessons for future law and practice, perhaps especially in relation to the wider justice, equity and fairness of decisions made under existing laws and legal frameworks.

Burrell and Kelly reflect on COVID-19 and the challenge it provides for innovation policy and law in the UK as a part of its long-term implications. They caution that the pandemic forces us to take a long overdue look at doing things differently. In particular, although the steps taken to develop COVID-19 vaccines have been hugely successful, those steps could have been fewer in number, and development far faster, if funding for research on SARS had not dried up as the risks of SARS receded. The authors explain how the UK's innovation model is overly patent-centric and market-focused, resulting in underinvestment in promising treatment opportunities and the 
skewing of priorities towards maximising shareholder value and other measures of immediate success. To take one example, the pandemic is likely to have prompted research bureaucrats within universities to recategorise research that was previously seen as wasteful, such as into novel corona viruses and the history of pandemics, as now being highly impactful. Tackling the problems with the UK's innovation model is only going to become more necessary due to climate change and the urgent need to develop mitigation technologies.

The importance of the pandemic for prompting reflection on remodelling law to future crises, and climate change in particular, is central to our final contribution by Sanchez-Graells, which discusses public procurement law. This law stems from the relevant European Union (EU) legislation. As such, although the discussion focuses on the situation in the English National Health Service, the discussion is relevant to the healthcare systems in EU member states, and areas of the public sector that have used the extremely urgent procurement exception to enable a response to the COVID-19 pandemic. Reflecting on the dysfunction and abuse of 'unregulated procurement' amidst COVID-19, Sanchez-Graells elucidates the need for reflection on public procurement rules to deal with impending challenges such as climate change.

\section{CONCLUSION}

The need for further reflection on the suitability and potential revision of the law to deal with emergencies of all kinds, not least climate change, resonates across the contributions towards this supplementary special issue. Such revision will need to meet the immensity of the task at hand. As outlined at the beginning of this introduction, the contributions to this special issue make clear that any successful attempt will need to give due regard to inter alia: law and constitutionalism; devolution; rights and responsibilities; whose voices count in discussion; power, position and vulnerability; and justice, equity and fairness. This special issue provides salient prompts and reference points for that immensely important discussion that will resonate long into the future. 